\title{
Numerical Analyses of Frost Heave on Gongbei Tunnel Constructed by Freeze-sealing Pipe Roof Method
}

\author{
Li Jian ${ }^{1,2}$ \\ ${ }^{1}$ Chang'an University, \\ Xi'an, China \\ ${ }^{2}$ Guangdong Nanyue Transportation Investment \& \\ Construction Co., Ltd., \\ Guangzhou, China \\ e-mail: lijian0757@126.com
}

\author{
Chen Jin \\ China Railway Eryuan Engineering Group Co. Ltd. \\ Chengdu, China \\ jackychen21@live.cn \\ Guo XiaoDong \\ Department of Geotechnical Engineering \\ Tongji University \\ Shanghai, China \\ 1332888gxd@tongji.edu.cn
}

\begin{abstract}
Gongbei Tunnel project at the Zhuhai link of Hong Kong-Zhuhai-Macau Bridge is to be constructed by a new construction method - "Freeze-Sealing Pipe Roof" (FSPR), serving as a forepoling system, combining with mining method. The primary purpose of this paper is to analyze the problem of frost heave in FSPR construction. The analyses of the influence of frost heave on the deformation of ground surface and the displacement of the pipes is conducted using numerical simulation. The results demonstrate that: (1) Within the actual buried depth of the tunnel, the buried depth has little impact on the deformation of pipe-roof and ground surface caused by frost heave; (2) Both the amount and the range of the deformation of ground is positively correlated to the thickness of the frozen-wall; (3) The uneven settlement of ground surface caused by frost heave is more obvious within $50 \mathrm{~m}$ away from the tunnel axis and therefore the gradient of surface elevation beyond $50 \mathrm{~m}$ is relatively slight; (4) The influence of the deformation of pipe-roof should be taken into consideration during the design of supporting structures as the deformation of piperoof caused by frost heave is closely related to the thickness of frozen-wall.
\end{abstract}

Keywords-Hong Kong-Zhuhai-Macau Bridge; Gongbei Tunnel; Freeze-sealing Pipe Roof Method; Frost heave; Displacement

\section{INTRODUCTION}

With the continuous development of urban modernization, it is more and more difficult to construct safely and reliably in the center of city. For sake of addressing the problem, many construction methods have been proposed and Freeze-Sealing Pipe Roof (FSPR) is one of those to decrease the influence of construction on surrounding buildings during construction.

Pipe-roofing method is an effective pre-supporting excavation method, which is often adopted in the construction of tunnels through weak grounds, under the protection of closed pipe-roof. Connected by interlocking, the interspaces between pipes are injected with grout in order to avoid seepage [1]. However, it is difficult to achieve a good ground water cut-off using injecting grout, when the tunnel route is curved [2].
As an effective water cut-off method, Artificial Ground Freezing (AGF) is widely used to create a strong, watertight frozen-wall by converting ground water into ice using artificial refrigeration [3]. The ice becomes a bonding agent, fusing together adjacent particles of soil or blocks of rock to increase their combined strength and make them impervious to water seepage. AGF has the advantages of high adaptability, high strength, low environmental impact and high water sealing performance [4].

Combining the advantages and disadvantages of PipeRoofing Method and AGF, one of the innovative construction methods is established, which is defined as Freeze-Sealing Pipe Roof Method (FSPR) [5]. In FSPR, pipe-roof is used to bear load, while the frozen soil between pipes serves to seal water. Thus, FSPR is capable of mitigating the impact on the surrounding environment, but also shows high adaptability, and meanwhile enjoys high adaptability, controllability and water sealing performance to overcome the problem of sealing water between pipes [6].

However, more attention should be paid to the frost heaving problem caused by moisture migration and volume expansion during freezing [7]. It will have an adverse effect on surrounding buildings, when the deformation of surface is relatively lager. Ever since frost heaving problem was proposed in Sweden, in 1925, its impact on the surrounding environment has been widely concerned, because of the need of construction in the cold region and the widely use of AGF in urban construction. Scholars have not only analyzed the process of frozen heave and its controlling factors, but also provided a number of frost prediction model based on finite element [8]. All These studies make it possible to control the frost heaving phenomenon better.

Up to now, few published papers or practical projects concerning the application of FSPR. Ueda [9] and Moriuchi [10] analyzed the force function and interaction mechanics performance between frozen soil and steel pipe. In engineering applications, there are merely a few similar projects referred to this kind of method in German. Nevertheless, such researches that are based on FSPR have 
not touched upon the influence of frost heave on surrounding environment. So, taking Gongbei Tunnel project of Zhuhai Link, Hong Kong-Zhuhai-Macao Bridge, as the study object, a 2D frost heaving analysis is necessary.

The magnitude of frost heave depends on the thickness of frozen-wall, cover thickness, moisture of soil, unfrozen water content, moisture migration and the type of soil [7]. While, the thickness of frozen-wall is the most direct one among them which can be used to control the magnitude of frost heave reliably. In this paper, the thickness of frozenwall is taken as the primary controlling variable; meanwhile, the impact of cover thickness on frost heave is also discussed because of the varied magnitude of cover thickness along the tunnel.

\section{ENGINEERING B ACKGROUND}

Gongbei Tunnel project is a double-deck integral tunnel in Zhuhai Link, Hong Kong-Zhuhai-Macao Bridge. The tunnel will cross the Gongbei Port, a place with a heavy traffic load and high underground water level closely connecting to the sea. According to the soil distribution of Zhuhai, the upper part of the ground that up line tunnel passes through is mainly fill, mucky soil, silty clay, and sand; the lower part of the ground is mainly silty clay. To reduce the construction influence on surrounding buildings and ensure the safety of construction, FSPR is selected as the construction method. As shown in Fig .1, the pipe-roof consists of a circle of steel pipes. The outer diameter of steel pipe is $1.44 \mathrm{~m}$ (some of them are $1.80 \mathrm{~m}$ ), the thickness is $0.016 \mathrm{~m}$, and the net space between pipes is about $0.25 \mathrm{~m}$.

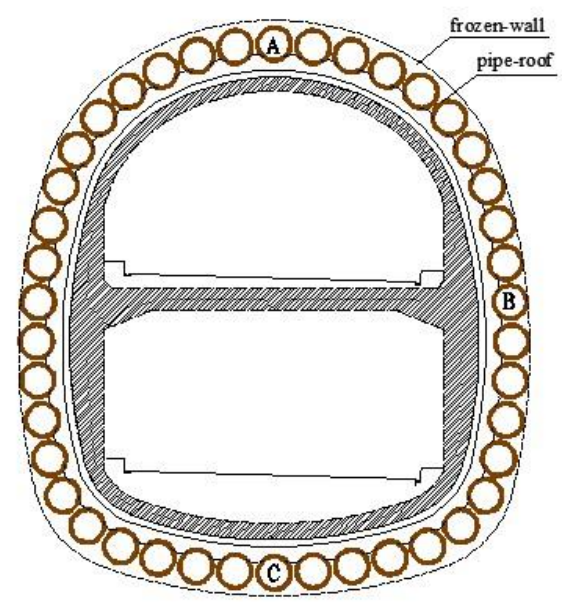

Figure 1. Cross-section layout of pipe-roof

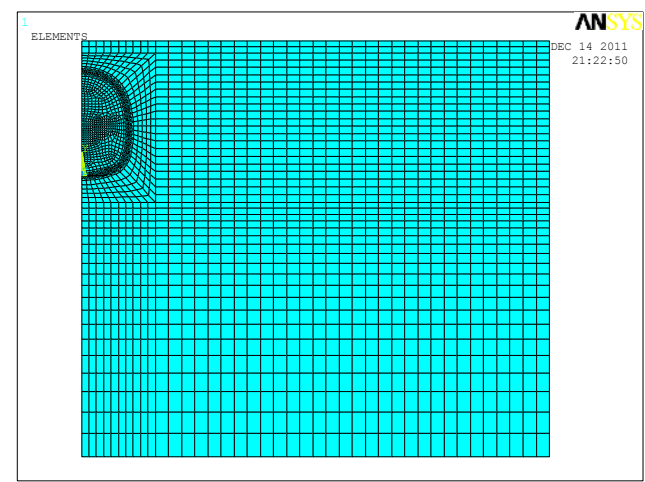

Figure 2. Model and mesh

\section{2D Frost HEAVING ANALYSES}

\section{A. Selection Of Numerical Model And Parameter}

The model can be simplified as a plane problem - 2D frost heaving analysis. According to the dimension of freezing areas and its influence scope and symmetry, a two-dimensional rectangular model, as shown in Fig .2, is established to calculate the displacement. In the $\mathrm{x}$-axis direction (horizontal), the width of model is $100.9 \mathrm{~m}$; in the $y$-axis direction (vertical): the distance between the bottom of the model and the center of pipe $\mathrm{C}$ is $60.74 \mathrm{~m}$ and the model were a total height of $88.70 \mathrm{~m}$ (when thickness of cover is 4.7 ) or $89.80 \mathrm{~m}$ (when thickness of cover is $5.8 \mathrm{~m}$ ). Also, the soil is assumed as homogeneous and isotropic elastic material.

According to the preliminary design data and geological information, the simulation parameters is equivalent to the average value of selected construction segment where the differential deformation is obvious at a rough estimate (the selection of Poisson's ratio is based on experience). Specific soil simulation parameters are shown in TABLE I. The outer diameter of steel pipe is 1.44 , the thickness is $0.016 \mathrm{~m}$, and the net space between pipes is about $0.25 \mathrm{~m}$. The elastic modulus of pipe is $2 \times 1011 \mathrm{~Pa}$, the Poisson's ratio of pipe is 0.3 , and the density of pipe is $7850 \mathrm{~kg} / \mathrm{m} 3$. On top of that, a $20 \mathrm{kPa}$ uniformly distributed load which is subjected to the ground surface is taken into consideration. The frost-heave ratio is $3.53 \%$.

TABLE I. PARAMETERS OF SOIL

\begin{tabular}{|c|c|c|c|c|}
\hline & $\begin{array}{c}\text { Density } \\
/ \mathbf{k g} / \mathbf{m 3}\end{array}$ & $\begin{array}{c}\text { Elastic } \\
\text { modulus } \\
/ \mathbf{M P a}\end{array}$ & $\begin{array}{c}\text { Poisson's } \\
\text { ratio }\end{array}$ & $\begin{array}{c}\text { water } \\
\text { content } / \%\end{array}$ \\
\hline $\begin{array}{c}\text { Unfrozen } \\
\text { soil }\end{array}$ & 1900 & 15 & 0.3 & 25 \\
\hline Frozen soil & 2000 & 150 & 0.24 & 4.5 \\
\hline
\end{tabular}

B. Simulation Groups

For sake of analyzing the effect of the thickness of frozen-wall and cover thickness on frost heave, based on the actual situation, the cover thickness of soil above the tunnel is varied between $4.7 \mathrm{~m}$ and $5.8 \mathrm{~m}$; frozen-wall thickness values are chosen as follows: $1.45 \mathrm{~m}, 1.8 \mathrm{~m}, 2.1 \mathrm{~m}$, $2.4 \mathrm{~m}, 2.7 \mathrm{~m}$ and $3.0 \mathrm{~m}$. 


\section{RESUlts AND ANALYSIS}

\section{A. The Displacement Of Ground}

Fig . 3 and Fig .4 demonstrate the distribution curves of uplift and horizontal displacement of ground surface. It is obvious that the maximum uplift of ground surface occurs in the surface corresponding to the axis of tunnel; however, horizontal displacement can achieve the highest value in the position about $5 \mathrm{~m}$ away from the outside of the piperoof. At the same time, the position of maximum uplift and maximum horizontal displacement remain unchanged while the thickness of frozen-wall varied within reasonable range. Also, Fig .5 provides the contours of displacement, when the cover thickness is $4.7 \mathrm{~m}$ and the thickness of frozen-wall is $3.0 \mathrm{~m}$, which show the distribution of displacement for the whole soil.

In the case of ignoring the impact of surrounding structure on frost heave, the uplift gradient can reach a higher value in the area within $50 \mathrm{~m}$ away from the tunnel axis, compared with outside the region. In case that the frozen-wall is $3 \mathrm{~m}$ in thickness, the differential settlement between the tunnel axis and the parallel lines $50 \mathrm{~m}$ away from the tunnel axis amounts to $84.4 \%$ of the maximum uplift. Therefore, both differential settlement caused by vertical displacement and horizontal displacement should be taken into consideration for the safety of buildings located within $50 \mathrm{~m}$ away from the tunnel axis; however, if the distance between surrounding building and the axis of tunnel is far more than $50 \mathrm{~m}$, lateral deformation analysis is enough.

At the same time, it is obvious that the differential settlement between the same points shows increased trends

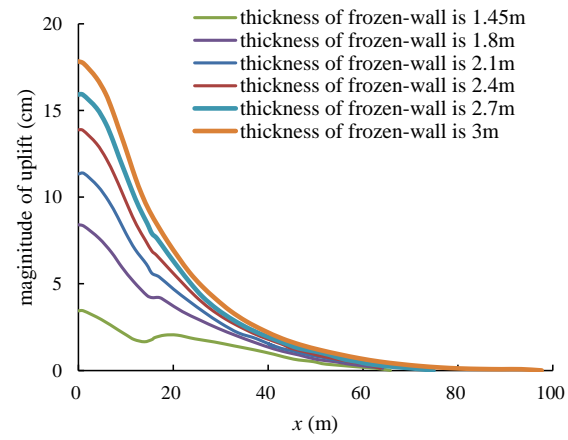

Figure 3. Distribution of uplift for ground surface (cover thickness of $4.7 \mathrm{~m})$

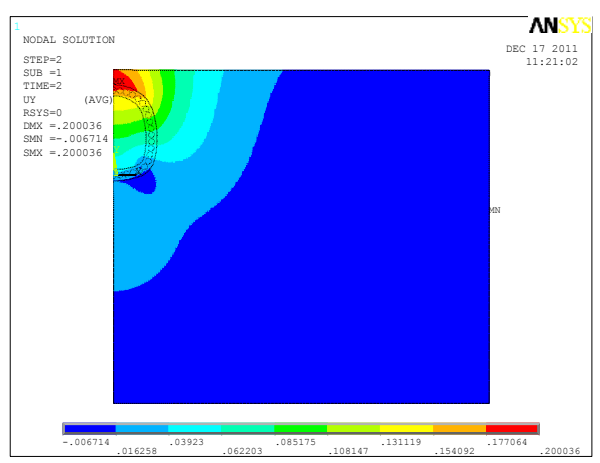

(a) Uplift contours with the increase of the thickness of frozen-wall. The uplift gradient of nearby building which is within $50 \mathrm{~m}$ away from the tunnel axis is relatively large, and it is sensitive to the thickness of frozen-wall. So, more attention should be paid to the differential settlement of surrounding buildings during freezing. As for the differential uplift of ground, it can be reduced by controlling the thickness of frozen-wall during construction.

Meanwhile, the curves of maximum horizontal displacement, maximum uplift of ground surface along with the change of frozen-wall thickness are shown in Fig .6 (a), respectively. Both Maximum horizontal displacement of surface and maximum vertical displacement are positively correlated to the thickness of frozen wall. However, when the cover thickness rises from $4.7 \mathrm{~m}$ to $5.8 \mathrm{~m}$, both the maximum horizontal displacement and the maximum vertical displacement have a slight decrease which can be ignored.

As can be seen from the relationship curves between the scope of the surface with displacement and the thickness of frozen-wall, shown in Fig .6 (b), the range of ground surface with displacement is positively correlated to the thickness of frozen wall. When cover thickness is varied from $4.7 \mathrm{~m}$ to 5.8 , the range of uplift surface increases by $2 \sim 3 \mathrm{~m}$, and the increment is positively correlated with the thickness of frozen-wall. The scope where the horizontal displacement of surface is measurable is basically immune to the increase of the cover thickness. Fig .6 (b) also transmit the idea that the range of surface where horizontal deformation is appreciable is bigger than the uplift brand.

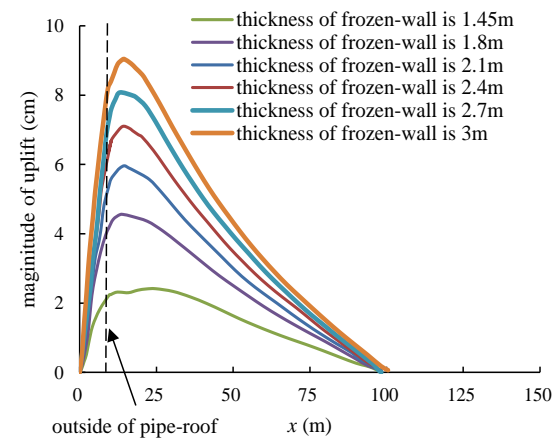

Figure 4. Distribution of horizontal displacement for ground surface (cover thickness of $4.7 \mathrm{~m}$ )

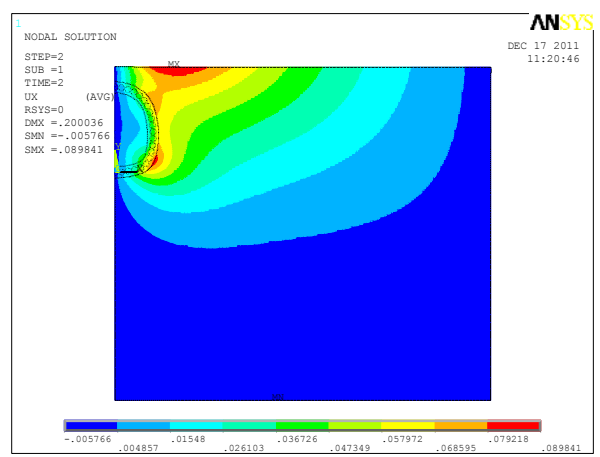

(b) Horizontal displacement contours

Figure 5. Displacement contours (cover thickness is $4.7 \mathrm{~m}$, thickness of frozen-wall is $3.0 \mathrm{~m}$ ) 


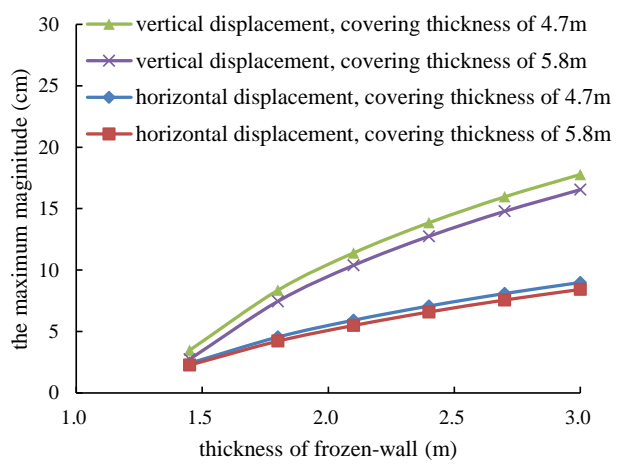

(a) Development curves of maximum magnitude of displacement

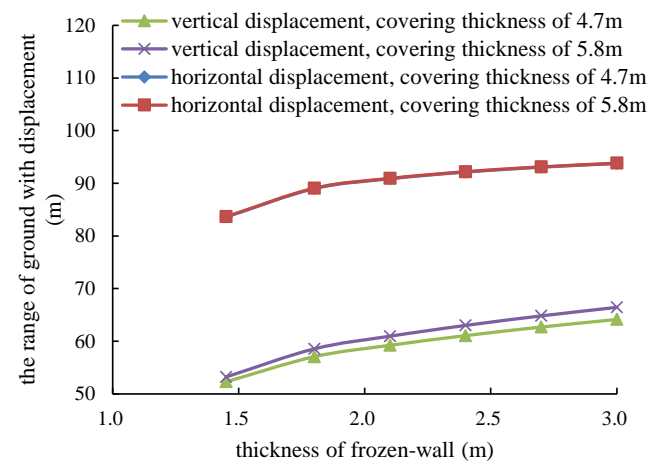

(b) Development curves of brand of surface with displacement

Figure 6. Development of displacement for ground surface (The direction deviating from the pipe-roof is set as the plus direction of horizontal displacement)

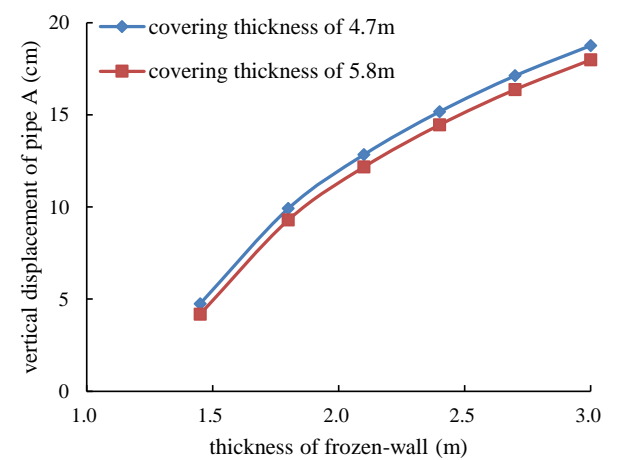

(a) Development curve of vertical displacement of pipe A

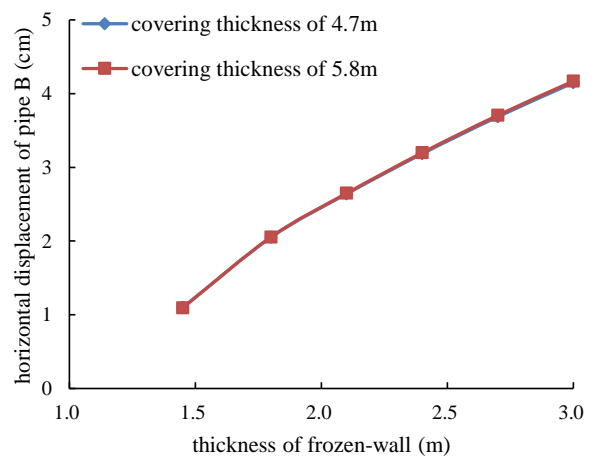

(c) Development curve of horizontal displacement of pipe B

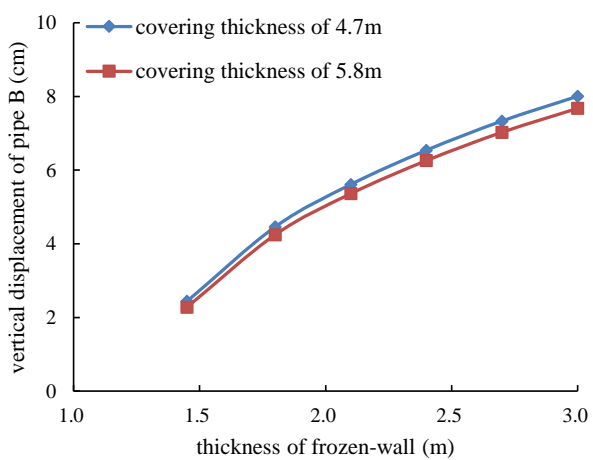

(b) Development curve of vertical displacement of pipe B

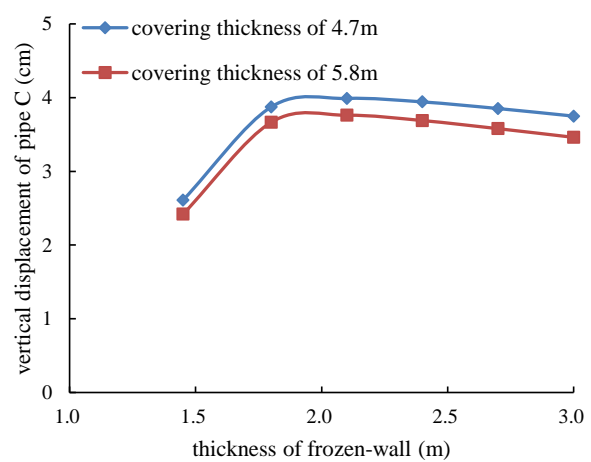

(d) Development curve of vertical displacement of pipe $\mathrm{C}$

Figure 7. Development of displacement of pipes (The uplift is set as the plus direction of vertical deformation, and direction deviating from the piperoof is set as the plus direction of vertical deformation)

\section{B. The Development of Pipe-Roof}

Based on the surface deformation distribution curves, shown in Fig .3 and Fig .4, pipe A, B and C are chosen as the typical cases to analyze the impact of frost heave on displacement of pipe-roof. Fig .7 provides the relationship graphs between displacement of typical pipes and thickness of frozen-wall (uplift is set as the plus direction of vertical displacement). The accurate position of typical pipes is shown in Fig. 1 .

As shown in Fig .7, uplift appears in pipe A, B and C with pipe $\mathrm{C}$ having an outward horizontal displacement. The changing curves show the relationship between the displacement of pipe and thickness of frozen-wall, which are almost positive except for the vertical settlement curve of pipe $\mathrm{C}$, which has an extreme point. It is partly because of boundary conditions and frost heaving force which is produced when pipe roof and frozen soil connected into a freeze envelope. Thus, the freeze envelope is expanding slowly during its upper shift, and the expanding of closed frozen body inhibits the uplift of pipe C. With the development of frozen-wall, the influence of expansion increases, which dues to the decrease curve of uplift settlement shown in Fig .7 (d). Meanwhile, the $18 \mathrm{~cm}$ vertical settlement of pipe A reminds designers of the influence of frost heave on the pipe-roof, when the thickness of frozen-wall reaches $3 \mathrm{~m}$. Fig .7 also demonstrates that cover thickness has little impact on the development of pipe-roof. 


\section{CONCLUSIONS}

According to the finite element analyses, the main conclusions obtained can be summarized as follows:

- The amount and range of ground deformation appreciable caused by frost heave appreciable are proportional to the thickness of frozen-wall. Meanwhile, the maximum uplift reaches $17.778 \mathrm{~cm}$ when the thickness of frozen-wall is $3.0 \mathrm{~m}$ and thickness of cover is $4.7 \mathrm{~m}$, which is too large to protect the surrounding buildings. Therefore, the thickness of frozen soil wall should be controlled in no more than $3.0 \mathrm{~m}$ to protect the surrounding buildings.

- The thickness of frozen-wall has little influence on the position where the maximum uplift and maximum horizontal displacement occur. The maximum of vertical displacement is discovered in the surface corresponding to the axis of tunnel and the horizontal displacement achieves its highest value in the position which is about $5 \mathrm{~m}$ away from the outside of the pipe-roof.

- Within the actual buried depth of tunnel, the buried depth has little impact on the deformation of roof-pipe and ground surface displacement caused by frost heave.

- The influence of the deformation of pipe-roof should be taken into consideration during the design of supporting structures and the thickness of frozen-wall should be controlled in order to reduce the deformation of pipe-roof for the deformation of pipe-roof caused by frost heave is closely related to the thickness of frozen-wall.

\section{ACKNOWLEDGMENT}

This work was financially supported by the National Natural Science Foundation of China (51478340) and
China Ministry of Communications Construction Science \& Technology Projects (2013318J11300).

\section{REFERENCES}

[1] H.H. Zhu, Z.G. Yan, X.Y. Li, X.Z. Liu and G.P. Shen. "Analysis of construction risks for pipe-roofing tunnel in saturated soft soil," Chinese Journal of Rock Mechanics and Engineering, Vol. 24(s2), Nov. 2005, pp. 5549-5554.

[2] K. Xing, T. Chen and C.B. Huang, "On new tubular roof method," Urban Mass Transit, Vol. 12, Sep. 2009, pp. 63-67. doi: 10.3969/j.issn.1007-869X.2009.08.019.

[3] R.J. Chen, G.D. Cheng, S.X. Li and et al, "Development and prospect of research on application of artificial ground freezing," Chinese Journal of Geotechnical Engineering, Vol. 22, Jan. 2000, pp. 40-44. doi: 10.3321/j.issn:1000-4548.2000.01.007.

[4] W. Ma, "Review and Prospect of the Studies of Ground Freezing Technology in China," Journal of glaciology and geocryology, Vol. 23, Sep. 2001, pp. 218-224. doi: 10.3969/j.issn.10000240.2001.03.002.

[5] X.D. Hu, S.Y. She, "Study of Freezing Scheme in Freeze-sealing Pipe Roof Method Based on Numerical Simulation of Temperature Field," International Conference on Pipelines and Trenchless Technology 2012: Better Pipeline Infrastructure for a Better Life (ICPTT 2012), American Society of Civil Engineers (ASCE), 2012, pp. 1798-1805. doi: 10.1061/9780784412619.181.

[6] S.Y. She. The preliminary study of freezing scheme in Freezsealing Pipe Roof Method based on unsteady conjugate heat transfer. Master Thesis, Tongji University, China.

[7] R. Lackner, A. Amon, and H. Lagger, "Artificial Ground Freezing of Fully Saturated Soil - Thermal Problem," J Journal of Engineering Mechanics, Vol. 131, Feb. 2005, pp. 211-220. doi: 10.1061/(ASCE)0733-9399(2005)131:2(211).

[8] X.Z. Xu, P. He and J.M. Zhang, "Progress in the Studies of Soil Freezing and Frost Heaving," Journal of glaciology and geocryology, Vol. 19 Sep. 1997, pp. 90-93.

[9] Y. Ueda, T. Ohrai and M. Yamamoto, "Improvement of bending strength of frozen soil beam reinforced by steel pip," Doboku Gakkai Ronbunshuu Vol. 2001, 2001, pp. 81-90.

[10] K. Moriuchi, Y. Ueda and T. Ohrai, "Study of the adfreeze between frozen soil and steel pipes for cutoff of water," Doboku Gakkai Ronbunshuu Vol. 64, 2008, pp. 294-306. 